\title{
Psychometric evaluation of the French version of the questionnaire attitudes towards morphine use; a cross-sectional study in Valais, Switzerland
}

\author{
Maria Ferreira ${ }^{1 *}$, Henk Verloo $^{2}$, Cédric Mabire ${ }^{3}$, Margarida Maria S Vieira ${ }^{4}$ and Pedro Marques-Vidal ${ }^{5}$
}

\begin{abstract}
Background: In Switzerland, nurses are allowed to prescribe and administer morphine in emergency situations without a doctor. Still, nurses and other health professionals are often reluctant to prescribe and administer morphine for pain management in patients. No valid French-speaking instrument is available in Switzerland to assess the attitudes of nurses and other health professionals towards the prescription and administration of morphine. In this study, we evaluated the psychometric properties of the French version of the questionnaire "Attitudes towards morphine use".
\end{abstract}

Methods: The instrument was derived from an Italian version. Forward and back translations of the questionnaire were performed. Item analysis and construct validity were assessed between April and December 2010 in a cross sectional study including five Swiss hospitals in a sample of 588 health professionals (533 nurses, mean age $38.3 \pm 10.2$ years). Thirty subjects participated in test-retest reliability.

Results: The time to complete the instrument ranged between 12 and 15 minutes and neither floor nor ceiling effect were found. The initial 24-item instrument showed an intraclass correlation (ICC) of 0.69 (95\% Cl: 0.64 to 0.73 , $\mathrm{P}<0.001$ ), and a Cronbach's a of 0.700. Factor analysis led to a six-component solution explaining $52.4 \%$ of the total variance. After excluding five items, the shortened version showed an ICC of 0.74 ( $95 \% \mathrm{Cl}, 0.70$ to $0.77, \mathrm{P}<0.001$ ) and a Cronbach's a of 0.741 . Factor analysis led to a five-component solution explaining $54.3 \%$ of the total variance. The five components were named "risk of addiction/dependence"; "operational reasons for not using morphine"; "risk of escalation"; "other (non-dependence) risks" and "external (non-operational) reasons". In test-retest, the shortened instrument showed an ICC of 0.797 ( $95 \%$ Cl, 0.630 to $0.911, \mathrm{P}<0.001)$ and a Cronbach's a of 0.797.

Conclusions: The 19-item shortened instrument assessing attitudes towards the prescription and administration of morphine showed adequate content and construct validity.

Keywords: Instrument validation, Morphine use, Attitudes, Psychometrics, Switzerland

\section{Background}

In hospitals, four out of five patients present with acute or chronic pain [1]. Pain management supposes far more than the simple prescription and administration of analgesic drugs, namely morphine and its derivatives [2,3]. Indeed, the health professionals' behavior is influenced by opposite factors such as the intention to completely relieve pain $[2,4]$ and many nonmedical factors such as concerns

\footnotetext{
* Correspondence: Maria_Ferreira77@hotmail.com

${ }^{1}$ Hôpital de Sion, Avenue Grand-Champsec 80, Case Postale 736, 1951 Sion, Switzerland

Full list of author information is available at the end of the article
}

regarding the deleterious health effects of morphine administration and the (unfounded) fear of legal consequences from possible deleterious effects [5-7].

Although several evidence-based guidelines have been issued $[2,8,9]$, inadequate attitudes towards morphine administration for pain relief (opiophobia) are still observed among health professionals [4,10-12]. Opiophobia can be defined as a set of inappropriate attitudes and beliefs regarding the deleterious effects of morphine administration for pain relief such as death, addiction, respiratory depression or urinary retention [13-16]. The main reasons for these inappropriate attitudes and beliefs are

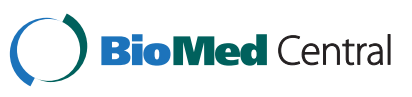


the lack of knowledge regarding morphine administration, a negative opinion about morphine due to substance abuse and the risk of developing addiction during morphine administration $[11,17]$. Hence, it is necessary to adequately characterize the beliefs and attitudes of health professionals regarding the prescription and administration of morphine and its derivatives. Several instruments have been proposed to assess attitudes regarding morphine prescription for pain relief $[5-7,18]$ but after a thorough literature search none has been adapted to French. Further, there is little information regarding their psychometric evaluation, even for nonFrench instruments $[5,6]$.

The "Attitudes face à l'utilisation de la morphine (AUM)" [Attitudes towards the use of morphine] was initially developed in 2003 by Musi \& Bionaz to assess attitudes towards the use and prescription of opioids as analgesic by nurses and doctors in the Italian-speaking Swiss canton of Tessin [7]. Most of these attitudes and beliefs have also been reported in other studies [19-22]. A Portuguese version has been applied among Portuguese health professionals of the Beira Interior region, South-East Portugal $[12,23]$ and a French version was recently developed and applied among student nurses in French-speaking Switzerland [24]. This instrument was preferred because it was available in three different languages (Italian, Portuguese and French), which would theoretically allow comparisons between countries. Further, literature search provided no other instrument assessing morphinophobia for Portuguese or French-speaking countries. Still, no thorough psychometric evaluation was performed.

Thus, the aim of this study was to analyze the psychometric properties of the French version of the "Attitudes face à l'utilisation de la morphine (AUM)" [Attitudes towards the use of morphine].

\section{Methods}

\section{Data collection and procedure}

The study was approved by the Internal Board Committee of the Wallis Hospital Center (Hôpital du Valais). The listing of all nurses and doctors was obtained from the human resources of the five hospitals, then a random sample of 1100 persons was drawn and the questionnaires were sent to them. Briefly, the questionnaires were sent to the different departments, and distributed to the persons on duty during a single day of the week. The day of sampling was decided by each head of the department. All participants gave their written informed consent before completing the instrument. The instrument was a self-administered tool and all completed instruments were anonymized prior to analysis and the completed instruments were kept in a locked room with restricted access.
Data were collected between April and December 2010 using a cross-sectional design conducted in five hospitals of the Swiss Canton of Valais: Sierre, Sion and Martigny hospitals, Clinique de St Claire and Centre Valaisan Pulmonaire. The heads of the departments were contacted and informed about the aim and the methodology of the study.

\section{Instrument}

The development of the original instrument (in Italian) has been described previously [7]. Briefly, it is composed of 26 items formulated as statements about prescription and administration of morphine, and the answers are provided in a 5-point Likert scale. All statements are scored in the same direction, i.e. ranging from $1=$ "Totally disagree" to $5=$ "Totally agree". A global score is derived by summing up all the responses, with a theoretical distribution of 104 possible score values, ranging between 26 and 130. The French version of the instrument was initially forward translated from Italian and then back-translated to ensure reliability of the statements. A first analysis [24] showed that two items, "It is necessary to evaluate pain (using a visual scale)" and "The doctor must inform the patient when prescribing a drug/medicine containing morphine", provided no information; hence, a 24-item instrument was developed and the current study is based on the 24-item French version. Also in this first analysis, of the questionnaire, the measured time to complete ranged between 20 and 25 minutes.

\section{Data analysis}

Statistical analysis was conducted using SPSS version 20.0 (IBM-SPSS, Armonk, NY, USA). Practicality was assessed by the time needed to complete the instrument and by feasibility, defined as the number of missing items [25]. The percentages of participants who scored at the floor (the worst $10 \%$ of score for the scale) or at the ceiling (the highest $10 \%$ of score for the scale) were also examined [26].

Reliability was assessed by the intra-class correlation coefficient (ICC) and its 95\% confidence interval. We defined reliability as an extent to which a variable or set of variables is consistent in what it is intended to measure [27]. The internal consistency of statements was evaluated using Cronbach's $\alpha$ coefficient. Internal consistency is defined as the correlation between the different statements of the instrument [27]. Cronbach values in the range of $0.81-1.00$ indicate 'almost perfect' agreement with $0.61-0.80$ indicating 'substantial', $0.41-0.60$ 'moderate', $0.21-0.40$ 'fair', $0.00-0.20$ 'slight' and $\leq 0.00$ indicates 'poor' agreement [27,28]. Intra-class correlation coefficients can be interpreted in the same manner. Reliability assessment was conducted in two stages: 1) using the 24-item instrument and 2) using the shortened version 
after item elimination. A similar analysis of the shortened version was performed after stratifying on profession (nurses and doctors).

Validity was assessed by factor analysis. We defined validity as an extent to which a measure or set of measures correctly represents the concepts of the study [27]. An exploratory factor analysis of the 24-item instrument was conducted. Bartlett's test of sphericity was used to assess if factor analysis was appropriate with the data analyzed. The Kaiser-Meyer-Olkin (KMO) index was used as a measure of sample adequacy, with KMO values $\geq 0.80$ for conducting exploratory factor analysis. $[27,29]$. The following criteria were employed to determine the optimal number of factors to extract: 1) scree plot observation; 2) Kaiser's eigenvalue $>1$ and 3) total variance explained $>50 \%$ [27]. The following statistical criterion was used to identify items eligible for elimination: low communality $(<0.35)$ and total variance explained $<50 \%$ [27]. Factor analysis with varimax rotation and Kaiser normalization was used as this method assumes that the explained variances among factors do not overlap [30]. After item elimination, another factor analysis was conducted to assess the validity of the shortened version.

Stability was evaluated using the test-retest procedure. As recommended by Hair et al. [27], one month after the first test a convenience sample of thirty subjects (26 nurses, 4 doctors) were enrolled for the test-retest reliability within the two departments of the same hospital (Sierre) and the time needed to complete the questionnaire was measured by one of the investigators (MF). Reliability was assessed using Pearson correlation coefficient.

\section{Results}

One thousand one hundred questionnaires were simultaneously distributed to the nurses and the doctors of the five hospitals, of which 588 (response rate: $53.5 \%, 533$ nurses and 55 doctors) were returned. The mean age of the 588 participants was 38.3 years $(S D=10.2$, range: $20-63)$. Most were women (84.0\%) and nurses (90.6\%), and the number of years as healthcare professionals (mean \pm standard deviation) was $13.9 \pm 10.0$ (median 12 , interquartile range 5-20).

Overall, 139 participants (23.6\%) had at least one missing answer which precluded the calculation of the overall score. Examination of the floor and ceiling effects indicated neither floor nor ceiling effect in the overall score (Figure 1).

\section{Original instrument (24-item version)}

Regarding reliability, the 24-item instrument showed an ICC of 0.69 ( $95 \%$ CI: 0.64 to $0.73, \mathrm{P}<0.001$ ).

The results of internal consistency for the whole instrument and the two constructs are summarized in Table 1. The 24-item instrument showed a Cronbach's $\alpha$ of 0.700 and three items $(5,12$ and 14) showed an improvement of internal consistency if removed; they are indicated in bold in Table 1. The English translation of the statements has not been psychometrically validated; please refer to the Additional file 1 for the valid French terms.

The results for validity showed a statistically significant Bartlett's test of sphericity $(2551.47, \mathrm{P}<0.001)$ and an adequate $\mathrm{KMO}$ value $(0.81)$. The initial explorative analysis on the 24-item instrument resulted in a six-factor rotated solution explaining $52.4 \%$ of the total variance (not shown). Items 10 and 15 showed an extraction communality $<0.35$ and were subsequently removed.

\section{Shortened instrument (19-item version)}

After removing 5 items, the psychometric properties of the shortened 19-item version of the instrument were assessed. Of the 588 participants, 117 (19.9\%) had at least one missing answer precluding the calculation of the overall score.

Regarding reliability, the shortened instrument showed an ICC of 0.74 (95\% CI, 0.70 to $0.77, \mathrm{P}<0.001)$. After sample stratification according to profession, the values were 0.74 ( $95 \% \mathrm{CI}$ : 0.70 to $0.78, \mathrm{p}<0.001$ ) for nurses and 0.74 (95\% CI: 0.60 to $0.84, \mathrm{p}<0.001)$ for doctors.

The results of internal consistency for the shortened instrument are summarized in Table 2. The shortened instrument showed a Cronbach's $\alpha$ of 0.741 and no item improved Cronbach's $\alpha$ upon removal. After sample stratification according to profession, the values for Cronbach's $\alpha$ was 0.739 for nurses and 0.760 for doctors (see also Additional file 2).

The results for validity are summarized in Table 3 . The English translation of the statements has not been psychometrically validated; please refer to the Additional file 1 for the valid French terms. The shortened version of the instrument showed a significant Bartlett's test of sphericity (1982.0, P <0.001) and a KMO value of 0.79 . A five-factor rotated solution was obtained, explaining $54.3 \%$ of the total variance. The five constructs were named "risk of addiction/dependence"; "operational reasons for not using morphine"; "risk of escalation"; "other (non-dependence) risks" and "external (non-operational) reasons". In nurses, the shortened version of the instrument showed a significant Bartlett's test of sphericity (1791.8, p < 0.001), a KMO value of 0.78 and a five-factor rotated solution explaining $54.4 \%$ of the total variance. In doctors, the shortened version of the instrument showed a significant Bartlett's test of sphericity (316.9, $\mathrm{p}<0.001)$, a $\mathrm{KMO}$ value of 0.60 , and a five-factor rotated solution explaining $64.9 \%$ of the total variance.

\section{Test-retest reliability}

The convenience sample of thirty subjects was aged $44.5 \pm 6.7$ years (mean \pm SD) and included 26 nurses and 4 doctors. Offering the same condition to complete the 


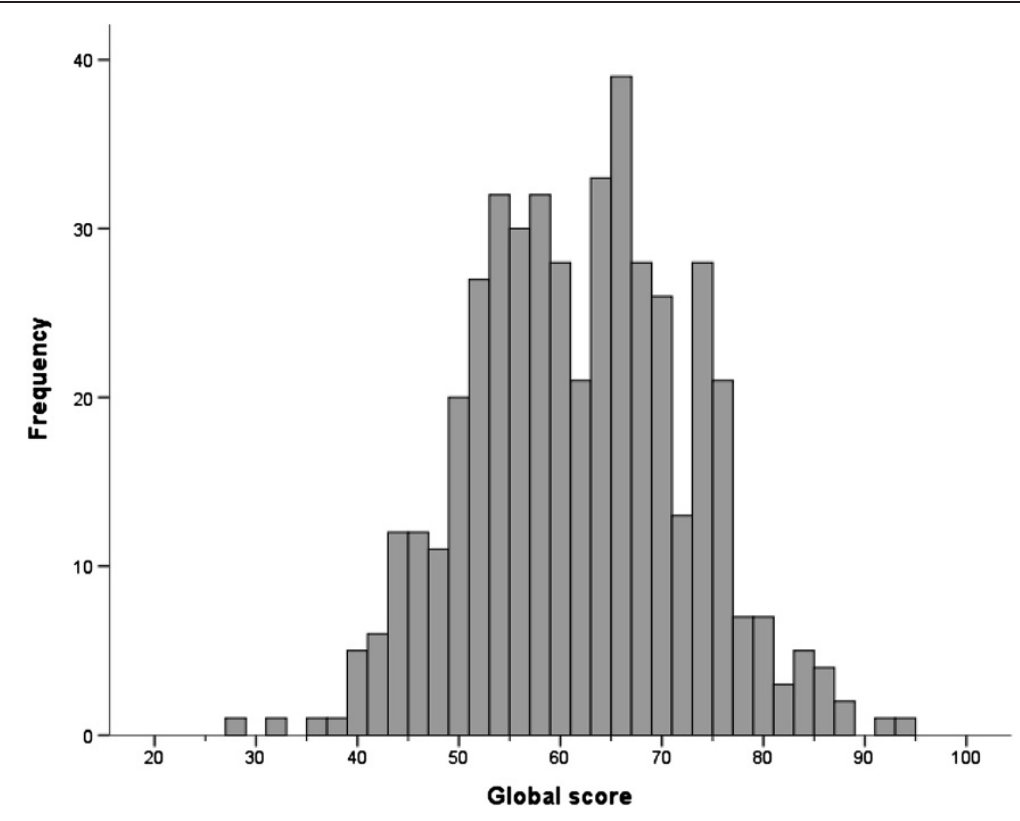

Figure 1 Distribution of the overall score for the 24-item instrument "Attitudes towards morphine use", French version.

shorten questionnaire, a strong Pearson correlation was found between the test and the retest sample $(r=0.72$, $\mathrm{p}<0.001)$. The shortened instrument showed an ICC of 0.797 (95\% CI, 0.630 to $0.911, \mathrm{P}<0.001$ ) and a Cronbach's $\alpha$ of 0.797 , indicating that the internal consistency remained stable after removing 5 items.

\section{Discussion}

To our knowledge, the AUM is the first instrument to evaluate the attitudes and beliefs of French-speaking health professionals regarding the prescription and administration of morphine. Overall, our results suggest that the shortened 19-item version of the AUM is a valid and reliable instrument that can be easily and quickly answered by health professionals without the need for specific filling instructions.

For over twenty years, several studies have tried to assess the attitudes of health professionals regarding morphine administration for pain management among hospitalized patients. The instrument of Brydon \& Asbury [18] assesses the beliefs and attitudes of health professionals to relieve pain among adult surgical patients but, to our knowledge, this instrument has never been psychometrically evaluated. The instrument of Broekmans et al. [5] is based on the one of Brydon and Asbury and assesses the nurses' attitudes towards pain relief using morphine. It consists of nine questions on addiction, side effects and use of opioids with the answers on a Likert scale ranging from 1 = "Totally agree" to $5=$ "Totally disagree". The authors reported a Cronbach's $\alpha$ of 0.70 , but again little psychometric data was provided. Finally, Edwards and al. assessed the determinants of registered nurses' intention to administer opioids to patients presenting with pain [6] using an instrument (Pain Management Survey) consisting of 28 items and a 5-point Likert scale for response options ranging from $1=$ "Totally disagree" to $5=$ "Totally agree". The authors reported a Cronbach $\alpha$ of 0.78 but again no further psychometric information was provided. Indeed, according to several authors $[4,12]$, further research is needed to assess attitudes towards the prescription and administration of morphine and its derivatives by health professionals.

\section{Original 24-item instrument}

The 24-item instrument showed good practicality, with no floor or ceiling effect; conversely, almost one quarter of participants had at least one missing answer, thus precluding the calculation of the overall score. This value is close to the ones reported for other instruments [31] and suggests that the longer the instrument, the more likely the participants will miss one answer.

Reliability and internal consistency were also adequate, as indicated by an ICC of 0.69 and a Cronbach's $\alpha$ of 0.700. Still, some items showed a poor correlation with the total and their deletion led to an improvement in Cronbach's $\alpha$. Factor analysis also showed that two items had communalities below the threshold value of 0.35 . Overall, the analysis suggested that the 24-item instrument could be shortened without losing its properties.

\section{Shortened 19-item instrument}

The shortened 19-item instrument showed a slightly lower percentage $(19.9 \%)$ of participants with at least one 
Table 1 24-item French version of the Attitudes towards morphine use questionnaire: internal consistency ( $n=458$ )

\begin{tabular}{|c|c|c|c|c|c|}
\hline & & Average* & SD & $\begin{array}{l}\text { Item-total } \\
\text { correlation }\end{array}$ & $\begin{array}{c}\text { Alpha if item } \\
\text { deleted }\end{array}$ \\
\hline 1 & It means it is serious & 2.03 & 1.20 & 0.309 & 0.670 \\
\hline 2 & It decreases life expectancy & 1.68 & 1.07 & 0.240 & 0.676 \\
\hline 3 & [The patient] can get used quickly and one takes the risk of increasing the dose & 2.39 & 1.27 & 0.512 & 0.651 \\
\hline 4 & Once treatment is initiated, there is the risk of being unable to stop & 1.67 & 1.05 & 0.439 & 0.661 \\
\hline 5 & All patients can be prescribed morphine regardless of the type of pain & 2.71 & 1.49 & -0.013 & 0.701 \\
\hline 6 & The early use of morphine makes it difficult to use any other treatment in severe pain & 2.48 & 1.39 & 0.397 & 0.660 \\
\hline 7 & IV administration is more effective than oral administration & 3.40 & 1.45 & 0.199 & 0.680 \\
\hline 8 & The patients are against the prescription of morphine & 2.63 & 1.13 & 0.248 & 0.675 \\
\hline 9 & The prescription of morphine means that there is no life expectation & 1.36 & 0.94 & 0.215 & 0.678 \\
\hline 10 & There are other more effective drugs, hence the use of morphine is not justified & 2.19 & 1.25 & 0.203 & 0.679 \\
\hline 11 & It is difficult to use and dose morphine & 1.93 & 1.16 & 0.295 & 0.671 \\
\hline 12 & For some types of pain, it is necessary to use morphine & 3.91 & 1.56 & -0.053 & 0.706 \\
\hline 13 & Morphine is a drug of last resort & 1.90 & 1.23 & 0.397 & 0.662 \\
\hline 14 & One can stop taking morphine whenever one wants to & 2.90 & 1.42 & -0.055 & 0.704 \\
\hline 15 & The prescription of morphine should be avoided for terminally ill patients & 1.22 & 0.75 & 0.188 & 0.680 \\
\hline 16 & Sensation of pain decreases with age in the elderly, which does not justify its use & 1.50 & 1.08 & 0.085 & 0.687 \\
\hline 17 & Risk of drug addiction & 2.71 & 1.46 & 0.398 & 0.659 \\
\hline 18 & Risk of delirium or euphoria & 3.15 & 1.38 & 0.311 & 0.669 \\
\hline 19 & Risk of drowsiness and sedation & 3.91 & 1.19 & 0.252 & 0.675 \\
\hline 20 & Risk of respiratory depression & 3.87 & 1.22 & 0.309 & 0.670 \\
\hline 21 & Legal risk compared to other drugs & 3.02 & 1.52 & 0.316 & 0.668 \\
\hline 22 & Risk of physical and/or psychological dependence & 3.09 & 1.35 & 0.400 & 0.660 \\
\hline 23 & Risk of discrimination & 2.36 & 1.48 & 0.137 & 0.686 \\
\hline 24 & Risk of urinary retention & 3.30 & 1.39 & 0.197 & 0.680 \\
\hline
\end{tabular}

*possible values from 1 to 5 .

missing value. It can thus be reasonably expected that the shortened instrument will be easier and possibly also quicker to complete.

The shortened 19-item version of the AUM presented an intra-class correlation of 0.740 and a Cronbach's $\alpha$ of 0.741 , both of which can be considered as "substantial" $[27,28]$. The internal consistency of the shortened instrument (Cronbach's $\alpha$ of 0.741 ) was higher than the instrument of Broekmans et al. (0.700) [5] but slightly lower than the instrument used by Edwards et al. (0.78) [6]. Still, considering the internal consistency obtained in the retest procedure (Cronbach's $\alpha$ of 0.797 ), it can be reasonably inferred that the shortened version of the AUM performs as well as other instruments previously used to assess attitudes towards the prescription and administration of morphine and its derivatives by health professionals. Further, the shortened instrument might be easier to use, as it only consists of 19 items, versus 28 for the instrument used by Edwards and col. [6]. Finally, the shortened instrument also presented a satisfactory degree of conformity and of internal consistency, with a between-item variance of 1.611 [29].

Factor analysis showed the shortened version to perform slightly better than the original one $(54.3 \%$ vs. $52.4 \%$ of the variance explained, using 5 components instead of 6). This result confirms that the instrument has adequate validity regarding the concepts of morphine use and administration and the perception of risks. The 19 items were grouped into five constructs, tentatively termed "risk of addiction/dependence"; "operational reasons for not using morphine"; "risk of escalation"; "other (non-dependence) risks" and "external (non-operational) reasons". The first one, which also showed the highest eigenvalue, clustered all items pertaining to addiction/dependence risk, while a second one clustered items more related to somatic risk. These findings suggest that Frenchspeaking health professionals consider separately the different risks related to morphine prescription, and that they appear to be more sensitive towards the risk of addiction than to somatic risk. 
Table 2 Shortened 19-item French version of the Attitudes towards morphine use questionnaire: internal consistency $(n=485)$

\begin{tabular}{|c|c|c|c|c|c|}
\hline & & Average* $^{*}$ & SD & $\begin{array}{l}\text { Item-total } \\
\text { correlation }\end{array}$ & $\begin{array}{c}\text { Alpha if item } \\
\text { deleted }\end{array}$ \\
\hline 1 & It means it is serious & 2.02 & 1.19 & 0.312 & 0.727 \\
\hline 2 & It decreases life expectancy & 1.68 & 1.07 & 0.249 & 0.731 \\
\hline 3 & [The patient] can get used quickly and one takes the risk of increasing the dose & 2.37 & 1.27 & 0.511 & 0.709 \\
\hline 4 & Once treatment is initiated, there is the risk of being unable to stop & 1.66 & 1.04 & 0.445 & 0.718 \\
\hline 6 & The early use of morphine makes it difficult to use any other treatment in severe pain & 2.48 & 1.39 & 0.413 & 0.717 \\
\hline 7 & IV administration is more effective than oral administration & 3.37 & 1.45 & 0.211 & 0.736 \\
\hline 8 & The patients are against the prescription of morphine & 2.64 & 1.13 & 0.198 & 0.735 \\
\hline 9 & The prescription of morphine means that there is no life expectation & 1.35 & 0.92 & 0.206 & 0.734 \\
\hline 11 & It is difficult to use and dose morphine & 1.93 & 1.16 & 0.326 & 0.726 \\
\hline 13 & Morphine is a drug of last resort & 1.91 & 1.23 & 0.400 & 0.719 \\
\hline 16 & Sensation of pain decreases with age in the elderly, which does not justify its use & 1.49 & 1.07 & 0.121 & 0.740 \\
\hline 17 & Risk of drug addiction & 2.70 & 1.45 & 0.385 & 0.720 \\
\hline 18 & Risk of delirium or euphoria & 3.15 & 1.37 & 0.295 & 0.728 \\
\hline 19 & Risk of drowsiness and sedation & 3.91 & 1.18 & 0.262 & 0.731 \\
\hline 20 & Risk of respiratory depression & 3.86 & 1.23 & 0.327 & 0.725 \\
\hline 21 & Legal risk compared to other drugs & 3.02 & 1.52 & 0.365 & 0.722 \\
\hline 22 & Risk of physical and/or psychological dependence & 3.09 & 1.35 & 0.407 & 0.718 \\
\hline 23 & Risk of discrimination & 2.35 & 1.47 & 0.201 & 0.738 \\
\hline 24 & Risk of urinary retention & 3.29 & 1.40 & 0.216 & 0.735 \\
\hline
\end{tabular}

Item numbering corresponds to the original 24-item instrument.

*possible values from 1 to 5 .

Similarly, while a single 18-item construct "morphine use and administration" was initially found [12], three different constructs were obtained. The first one, "risk of escalation" clustered items related to the fact that once a morphine treatment is initiated, a dose escalation is necessary with potential deleterious effects on life expectancy. The second construct, "operational reasons for not using morphine" clustered items related to perceived in-hospital obstacles to use morphine, such as its difficulty to dose and its association with end of life and palliative care. Finally, the third one "external (non-operational) reasons for not using morphine" clustered items such as the fact that patients are against the prescription of morphine.

Overall, our results suggest that the shortened version of the AUM might provide interesting information regarding beliefs, reasons for not using and perceived risks of using morphine among health professionals. The reliability and internal consistency is comparable for nurses and doctors, suggesting that it can be applied to both health professions. Its shorter size will also increase practicality, with a decreased time for completion and a lower rate of missing answers. Nevertheless, other hypotheses must be verified and further studies on the validity of the instrument must be conducted.

\section{Strengths and limitations}

This study has some limitations worth mentioning. First, the participation rate $(53.5 \%)$ was rather low, and it is possible that non-responders might have a different response pattern than responders. Still, this participation rate is comparable or even higher than the ones reported by other psychometric studies [32,33]. Second, the study was geographically limited, and the sample might not be representative of all Swiss French-speaking health professionals. Still, making such a psychometric study in a multicenter setting was beyond our logistic capacities, and it would be of interest to apply this instrument in other Frenchspeaking regions. Third, it is possible that cultural dimensions might influence the psychometric value of the instrument. Again, only the application of the instrument in other settings will allow a precise evaluation of the cultural dimensions regarding the answers. Fourth, no information was collected regarding highest level of education. Still, as in order to work as a nurse/doctor all foreign diplomas have to be validated, it is likely that all participants had at least an educational level comparable to those of Swiss doctors and nurses. Fifth, the content and face validity have not yet been reviewed. It is currently being done by two nursing professors (experts in pain management) 
Table 3 Results of the factor analysis of the shortened 19-item instrument

\begin{tabular}{|c|c|c|c|c|c|c|}
\hline & & 1 & 2 & 3 & 4 & 5 \\
\hline & "Risk of addiction/dependence" (eigenvalue $=3.580, \%$ variance explained $=18.8$ & & & & & \\
\hline 17 & Risk of drug addiction & 0.776 & & & & \\
\hline 18 & Risk of delirium or euphoria & 0.700 & & & & \\
\hline 19 & Risk of drowsiness and sedation & 0.543 & & & & \\
\hline \multirow[t]{2}{*}{22} & Risk of physical and/or psychological dependence & 0.770 & & & & \\
\hline & "Operational reasons for not using morphine" (eigenvalue $=2.905, \%$ variance e & & & & & \\
\hline 9 & The prescription of morphine means that there is no life expectation & & 0.522 & & & \\
\hline 11 & It is difficult to use and dose morphine & & 0.662 & & & \\
\hline 13 & Morphine is a drug of last resort & & 0.516 & & & \\
\hline 21 & Legal risk compared to other drugs & & 0.698 & & & \\
\hline \multirow[t]{2}{*}{23} & Risk of discrimination & & 0.707 & & & \\
\hline & "Risk of escalation" (eigenvalue $=1.656, \%$ variance explained $=8.7$ ) & & & & & \\
\hline 1 & It means it is serious & & & 0.598 & & \\
\hline 2 & It decreases life expectancy & & & 0.698 & & \\
\hline 3 & [The patient] can get used quickly and one takes the risk of increasing the dose & & & 0.654 & & \\
\hline 4 & Once treatment is initiated, there is the risk of being unable to stop & & & 0.564 & & \\
\hline \multirow[t]{2}{*}{6} & The early use of morphine makes it difficult to use any other treatment in severe pain & & & 0.525 & & \\
\hline & "Other (non-dependence) risks" (eigenvalue $=1.111, \%$ variance explained $=5.8$ ) & & & & & \\
\hline 7 & IV administration is more effective than oral administration & & & & 0.593 & \\
\hline 20 & Risk of respiratory depression & & & & 0.613 & \\
\hline \multirow[t]{2}{*}{24} & Risk of urinary retention & & & & 0.668 & \\
\hline & "External (non-operational) reasons" (eigenvalue $=1.060, \%$ variance explained $=$ & & & & & \\
\hline 8 & The patients are against the prescription of morphine & & & & & 0.707 \\
\hline 16 & Sensation of pain decreases with age in the elderly, which does not justify its use & & & & & -0.501 \\
\hline
\end{tabular}

Item numbering corresponds to the 24-item instrument. Results expressed as the highest factor loading for each component. Statistical analysis by factor analysis with varimax rotation and Kaiser normalization.

of the Applied University of Nursing sciences La Source in Lausanne. Finally, longitudinal studies assessing the results of the instrument before and after an educational intervention on the prescription and administration of morphine should also be considered [34].

Among the strengths, the study was conducted in a large sample (588), considerably higher than the recommended 5 participants per item [27] and also higher than previous studies [5]. Further, the test-retest analysis showed a Cronbach's $\alpha$ of 0.797 , higher than the values reported for other instruments $[5,6]$.

\section{Conclusions}

Overall, our results suggest that the shortened version of the French questionnaire on attitudes towards the use of morphine is a valid instrument to assess attitudes and beliefs towards the prescription and administration of morphine among health professionals. The instrument allows the assessment of the main attitudes that might deter health professionals from using morphine in pain management and can be used in different settings among French-speaking countries to compare attitudes and to assess the effectiveness of training and educational programs regarding the prescription and administration of morphine.

\section{Additional files}

Additional file 1: French version of the questionnaire Attitudes towards morphine use.

Additional file 2: Shortened 19-item French version of the Attitudes towards morphine use questionnaire: internal consistency, stratified by profession (nurses and doctors).

\section{Competing interests}

The authors declare that they have no competing interests.

\section{Authors' contributions}

MF, HV and CB were responsible for the study conception and design. MF, CB and HV performed the data collection. MF and PMV performed the data analysis. MF and PMV were responsible for the drafting of the manuscript. HV, CB and MMSV made critical revisions to the paper for important intellectual content. All authors have read and approved this version of the manuscript. 


\section{Funding}

This research received no specific grant from any funding agency in the public, commercial or not-for-profit sectors.

\section{Author details}

'Hôpital de Sion, Avenue Grand-Champsec 80, Case Postale 736, 1951 Sion, Switzerland. ${ }^{2}$ Haute Ecole de Santé La Source, Avenue Vinet 30, 1004 Lausanne, Switzerland. ${ }^{3}$ Haute Ecole de Santé Vaud, Unité de recherche en Santé, Av. de Beaumont 21, 1011 Lausanne, Switzerland. ${ }^{4}$ Universidade Católica Portuguesa, Instituto de Ciências da Saúde, Palma de Cima, 1649-023 Lisboa, Portugal. Institute of Social and Preventive Medicine, University Hospital of Lausanne, route de la Corniche 10, 1010 Lausanne, Switzerland.

Received: 27 April 2013 Accepted: 6 January 2014 Published: 10 January 2014

\section{References}

1. Marchand S: Le phénomène de la douleur. 2nd edition. Montréal, Canada: Chenelière Éducation: 2009.

2. Hanks GW, Conno F, Cherny N, Hanna M, Kalso E, McQuay HJ, Mercadante S, Meynadier J, Poulain P, Ripamonti C, et al: Morphine and alternative opioids in cancer pain: the EAPC recommendations. Br J Cancer 2001, 84(5):587-593.

3. Barkin RL, Barkin SJ, Barkin DS: Perception, assessment, treatment, and management of pain in the elderly. Clin Geriatr Med 2005, 21(3):465-490. v.

4. Bandieri E, Chiarolanza A, Luppi M, Magrini N, Marata AM, Ripamonti C Prescription of opioids in Italy: everything, but the morphine. Ann Oncol 2009, 20(5):961-962

5. Broekmans S, Vanderschueren S, Morlion B, Kumar A, Evers G: Nurses' attitudes toward pain treatment with opioids: a survey in a Belgian university hospital. Int J Nurs Stud 2004, 41(2):183-189.

6. Edwards HE, Nash RE, Najman JM, Yates PM, Fentiman BJ, Dewar A, Walsh AM, McDowell JK, Skerman HM: Determinants of nurses' intention to administer opioids for pain relief. Nurs Health Sci 2001, 3(3):149-159.

7. Musi $M$, Bionaz $A$ : Les mythes de la morphine. Une étude auprès de la population générale, des infirmiers/ères et des médecins en Vallée d'Aoste. Infokara 2003, 4:1-18.

8. Gordon DB, Pellino TA, Miaskowski C, McNeill JA, Paice JA, Laferriere D, Bookbinder M: A 10-year review of quality improvement monitoring in pain management: recommendations for standardized outcome measures. Pain Manag Nurs 2002, 3(4):116-130.

9. World Health Organization: Cancer pain relief with a guide to opioid availability. Geneva, Switzerland: World Health Organization; 1996:63.

10. McCaffery M, Ferrell BR: Opioids and pain management: what do nurses know? Nursing 1999, 29(3):48-52

11. Ripamonti C, De Conno F, Blumhuber H, Ventafridda V: Morphine for relief of cancer pain. Lancet 1996, 347(9010):1262-1263.

12. Verloo H, Mpinga EK, Ferreira M, Rapin CH, Chastonay P: Morphinofobia: the situation among the general population and health care professionals in North-Eastern Portugal. BMC Palliat Care 2010, 9:15.

13. Covington EC: Opiophobia, opiophilia, opioagnosia. Pain Med 2000, 1(3):217-223.

14. Elliott TE, Elliott BA: Physician attitudes and beliefs about use of morphine for cancer pain. J Pain Symptom Manage 1992, 7(3):141-148.

15. Tennant F: In Overcoming opiophobia \& doing opioids right. Volume 2012. Edited by Leavitt SB. Glenview, IL, USA; 2007:6.

16. Gallagher J, O'Gara C, Sessay M, Luty J: Nurse prescribing in addiction services: client benefits. Nurs Stand 2006, 20(48):42-44.

17. Howell D, Butler L, Vincent L, Watt-Watson J, Stearns N: Influencing nurses' knowledge, attitudes, and practice in cancer pain management. Cancer Nurs 2000, 23(1):55-63.

18. Brydon CW, Asbury AJ: Attitudes to pain and pain relief in adult surgical patients. Anaesthesia 1996, 51:279-281.

19. Potter M, Schafer S, Gonzalez-Mendez E, Gjeltema K, Lopez A, Wu J, Pedrin $\mathrm{R}$, Cozen M, Wilson R, Thom D, et al: Opioids for chronic nonmalignant pain. Attitudes and practices of primary care physicians in the UCSF/ Stanford Collaborative Research Network. University of California, San Francisco. J Fam Pract 2001, 50(2):145-151.

20. Nwokeji ED, Rascati KL, Brown CM, Eisenberg A: Influences of attitudes on family physicians' willingness to prescribe long-acting opioid analgesics for patients with chronic nonmalignant pain. Clin Ther 2007, 29(Suppl):2589-2602.

21. Morley-Forster PK, Clark AJ, Speechley M, Moulin DE: Attitudes toward opioid use for chronic pain: a Canadian physician survey. Pain Res Manag 2003, 8(4):189-194

22. Salvato C, Aretini G, Serraglia D, Terrazzani G, Debetto P, Giusti P. Chinellato A: Opioid prescription for terminally ill outpatients in a district of northern Italy: a retrospective survey. Pharmacol Res 2003, 48(1):75-82.

23. Verloo H, Ferreira M, Mpinga EK, Chastonay P, Rapin CH: Opiophobie: Etat des lieux auprès des soignants à Beira Interior. Douleur et Analgésie 2009, 22:186-195.

24. Verloo H, Cohen C, Borloz C, Mpinga EK, Chastonay P: Risks associated with the use of morphine as analgesia: attitudes and perceptions amongst nursing students in French-speaking Switzerland. Nursing: Res Rev 2013, 3:1-8.

25. Jansen AJ, Essink-Bot ML, Duvekot JJ, van Rhenen DJ: Psychometric evaluation of health-related quality of life measures in women after different types of delivery. J Psychosom Res 2007, 63(3):275-281.

26. Bennet SJ, Oldridge NB, Eckert GJ, Embree JL, Browning S, Hou N, Deer M, Murray MD: Discriminant properties of commonly used quality of life measures in heart failure. Qual Life Res 2002, 11(4):349-359.

27. Hair JF Jr, Black WC, Babin BJ, Anderson RE: Multivariate data analysis. 7th edition. Upper Saddle River, New Jersey, USA: Pearson Global Editions; 2010.

28. Nunnally JC: Psychometric theory. 2nd edition. New York, USA: McGraw-Hill; 1978.

29. Streiner DL, Norman GR: Health measurement scales: a practical guide to their development and use. 4th edition. New-York, USA: Oxford University Press; 2008.

30. Pett MA, Lackey NR, Sullivan JJ: Making sense of factor analysis: the use of factor analysis for instrument development in health care research. Thousand Oaks, CA, USA: SAGE Publications, Inc; 2003.

31. Denkinger MD, IgI W, Coll-Planas L, Nikolaus T, Bailer S, Bader A, Jamour M Practicality, validity and sensitivity to change of fear of falling self-report in hospitalised elderly-a comparison of four instruments. Age Ageing 2009, 38(1):108-112.

32. Burkhart L, Schmidt L, Hogan N: Development and psychometric testing of the Spiritual Care Inventory instrument. J Adv Nurs 2011, 67(11):2463-2472.

33. Edvardsson D, Sandman PO, Rasmussen B: Swedish language Person-centred Climate Questionnaire - patient version: construction and psychometric evaluation. J Adv Nurs 2008, 63(3):302-309.

34. Young A, Alfred KC, Davignon PP, Hughes LM, Robin LA, Chaudhry HJ: Physician survey examining the impact of an educational tool for responsible opioid prescribing. J Opioid Manag 2012, 8(2):81-87.

\section{doi:10.1186/1472-6955-13-1}

Cite this article as: Ferreira et al:: Psychometric evaluation of the French version of the questionnaire attitudes towards morphine use; a cross-sectional study in Valais, Switzerland. BMC Nursing 2014 13:1.

\section{Submit your next manuscript to BioMed Central and take full advantage of:}

- Convenient online submission

- Thorough peer review

- No space constraints or color figure charges

- Immediate publication on acceptance

- Inclusion in PubMed, CAS, Scopus and Google Scholar

- Research which is freely available for redistribution 